\title{
Platform Google Earth Engine Untuk Pemetaan Suhu Permukaan Daratan Dari Data Series Modis
}

\author{
Luhur Moekti Prayogo \\ Magister Teknik Geomatika, Fakultas Teknik - Universitas Gadjah Mada, Indonesia, 55281 \\ Email: luhur.moekti.prayogo@mail.ugm.ac.id
}

\begin{abstract}
Urban Heat Island (UHI) is a factor that affects the earth's surface temperature. The UHI phenomenon causes the city's land surface temperature to be higher due to anthropogenic factors. The identification of land surface temperatures caused by UHI can be made using cloud-based remote sensing techniques. This study aims to map the land surface temperature of the northern coastal area of Surabaya and its surroundings with MODIS multitemporal images in 2001-2020 using the Google Earth Engine Platform. The location was chosen because it is suspected that the temperature will increase due to development activities, which generally occur in all parts of Indonesia. From this study, it can be concluded that there is a significant increase in heat from year to year. In the north coast of Surabaya, East Java, in 2001, the surface temperature was $30^{\circ} \mathrm{C}$, located in the northern part. In 2011 the temperature increased and spread to the southern region. Then the highest temperature is shown in 2020, where almost the entire area has heat above $28^{\circ} \mathrm{C}$. This research indicates that the Google Earth Engine platform is effective for mapping land surface temperatures. Further research is needed on the use of data measured directly in the field and higher spatial resolution imagery to determine the accuracy of the Google Earth Engine platform.
\end{abstract}

Keywords: Urban Heat Island (UHI), Mapping, MODIS, Google Earth Engine

\begin{abstract}
Abstrak. Urban Heat Island (UHI) merupakan faktor yang mempengaruhi suhu permukaan bumi. Fenomena UHI menyebabkan suhu permukaan daratan kota lebih tinggi karena faktor antropogenik. Indentifikasi suhu permukaan daratan yang disebabkan oleh UHI dapat dilakukan dengan teknik penginderaan jauh berbasis cloud. Penelitian ini bertujuan untuk memetakan suhu permukaan daratan wilayah pesisir utara Surabaya dan sekitarnya dengan citra multi temporal MODIS tahun 2001-2020 menggunakan Platform Google Earth Engine. Lokasi tersebut dipilih karena diduga mengalami peningkatan suhu akibat aktivitas pembangunan yang umumnya juga terjadi di seluruh wilayah Indonesia. Dari penelitian ini dapat disimpulkan bahwa terjadi peningkatan panas yang cukup signifikan dari tahun ke tahun. Di pesisir utara Surabaya, Jawa Timur, pada tahun 2001 suhu permukaan pada kisaran $30^{\circ} \mathrm{C}$ terletak dibagian utara. Pada tahun 2011 suhu meningkat dan menyebar ke wilayah bagian selatan. Kemudian suhu paling tinggi ditunjukkan pada tahun 2020, dimana hampir keseluruhan wilayah memiliki panas diatas $28^{\circ} \mathrm{C}$. Dari penelitian ini dapat diketahui bahwa penggunaan platform Google Earth Engine efektif untuk pemetaan suhu permukaan daratan. Perlu adanya penelitian lanjutan mengenai penggunaan data yang diukur langsung di lapangan dan citra resolusi spasial lebih tinggi agar mengetahui akurasi yang dihasilkan dari platform Google Earth Engine.
\end{abstract}

Kata Kunci: Urban Heat Island (UHI), Pemetaan, MODIS, Google Earth Engine 


\section{Pendahuluan}

Surabaya merupakan salah satu kota yang terletak di Provinsi Jawa Timur dengan letak geografis 112036' 1120 54' BT dan 7021' LS dan luas daratan kurang lebih 326,37 $\mathrm{km}^{2}$ (Suharyo \& Hidayah, 2019). Pada bagian utara, Surabaya termasuk dalam kawasan pesisir dimana kebanyakan industri dibangun di wilayah tersebut. Tidak hanya itu, bagian pesisir utara juga memiliki pelabuhan "tanjung perak" yang menjadi pelabuhan utama di wilayah tersebut. Menurut Media Indonesia (2019), pesisir utara Surabaya akan mengalami pertumbuhan ekonomi dan sebagai tempat wisata baru bagi ibu kota Jawa Timur ini. Hal ini disebabkan oleh pembangunan jalan baru yang membentang sepanjang $22 \mathrm{~km}$ yang terhubung dengan tol Perak. Dengan dilakukan pembangunan pada wilayah Surabaya, kondisi pesisir utara Surabaya diduga mengalami berbagai perubahan yang umumnya juga terjadi di wilayah pesisir Indonesia (Suharyo \& Hidayah, 2019).

Wilayah yang dilakukan pembangunan, tentu tidak lepas dari alih fungsi lahan yang akan memberikan pengaruh terhadap kondisi kawasan tersebut. Lahan yang awalnya kosong dan dipenuhi vegetasi berubah menjadi perumahan dan gedung-gedung yang tentunya keberadaan vegetasi akan semakin berkurang. Dampak nyata dari wilayah yang dilakukan pembangunan salah satunya adalah suhu permukaan daratan (Sari \& Wenang Anurogo, 2018). Berkurangnya vegetasi atau lahan terbuka hijau menjadikan suatu wilayah mengalami kenaikan suhu. Hal ini tentunya akan mempengaruhi kualitas lingkungan. Menurut Rizki et al. (2017); Sari \& Wenang Anurogo (2018), bahwa pengetahuan mengenai suhu permukaan darat menjadi penting, karena sebagai landasan pembangunan wilayah agar ruang vegetasi hijau tidak hilang dimana menjadi indikator baik buruknya suatu wilayah. Fariz et al. (2019) menyatakan Urban Heat Island (UHI) merupakan faktor yang mempengaruhi suhu permukaan bumi. Fenomena UHI menyebabkan suhu permukaan daratan kota lebih tinggi karena faktor antropogenik(Abutaleb et al., 2015; Fariz et al., 2019). Indentifikasi karakterisasi dapat dilakukan secara spasial melalui teknik penginderaan jauh (Fariz et al., 2019; Jeevalakshmi et al., 2017). Dewasa ini, perkembangan dari teknik penginderaan jauh ditandai dengan pemrosesan citra berbasis cloud dimana penyimpanan berupa hardisk dan memori membuat tidak fleksibel dan sangat terbatas dalam pemrosesan. Pemrosesan berbasis cloud saat ini yang populer adalah menggunakan Google Earth Engine (GEE). Gorelick et al. (2017) menyatakan bahwa GEE merupakan platform yang menawarkan analisis data lingkungan berbasis cloud dengan gratis/ open source. Platform ini memiliki keunggulan yaitu telah menyediakan Application Programming Interface (APIs) yang menggunakan JavaScript dan Python serta dapat dihostkan ke Github.

Penelitian mengenai suhu permukaan darat menggunakan teknik penginderaan jauh pernah dilakukan oleh Sari \& Wenang Anurogo (2018) menggunakan citra Landsat 8 di pulau Batam dengan metode Split Window Algorithm (SWA). Penelitian tersebut menghasilkan bahwa kelas vegetasi memiliki suhu rata-rata $16.8-22.4{ }^{\circ} \mathrm{C}$, dan kelas tak bervegetasi memiliki suhu rata-rata $22.4-23.6{ }^{\circ} \mathrm{C}$. Kemudian pada 
kelas pemukiman memiliki suhu daratan yang tinggi yaitu berkisar $23.6-29.2{ }^{\circ} \mathrm{C}$. Selanjutnya penelitian Fariz et al. (2019) yang dilakukan di kota Pekalongan dengan membandingkan band thermal citra Landsat 7 dan 8 . Penelitian tersebut untuk mengetahui perubahan secara temporal suhu permukaan daratan. Dari penelitian tersebut menunjukkan bahwa citra Landsat 8 menghasilkan estimasi nilai suhu lebih baik dibandingkan dengan Landsat 7 dengan kenaikan suhu di kota Pekalongan dari tahun 2015 - 2019 mencapai $0.6^{\circ} \mathrm{C}$. Firdaus et al. (2019) juga melakukan penelitian di kota Pontianak dengan eksplorasi band thermal citra Landsat yang kemudian dihubungkan dengan Normalized Difference Built Index (NDBI) dan Normalized Difference Vegetation Index (NDVI). Penelitian tersebut menghasilkan bahwa menurunnya luasan vegetasi mengakibatkan suhu permukaan daratan menjadi tinggi. Dari penjelasan diatas, perlu adanya kajian khusus mengenai pemetaan suhu permukaan daratan menggunakan teknologi baru dalam teknik penginderaan jauh yaitu berbasis cloud. Teknik ini dipilih karena masih tergolong jarang dilakukan di Indonesia sehingga kelebihan dan kekurangannya belum banyak diketahui. Lokasi penelitian dilakukan di pesisir utara Surabaya dan sekitarnya, karena diduga mengalami kenaikan suhu setiap tahunnya yang disebabkan efek dari pembangunan wilayah.

\section{Materi dan Metode}

Penelitian ini dilaksanakan di pesisir utara Surabaya dan sekitarnya dengan letak geografis yaitu pada Latitude: 07015'34" dan Longitude: $112^{\circ} 45^{\prime} 00^{\prime \prime}$. Gambar 1 merupakan lokasi penelitian yang ditampilkan menggunakan ESRI world imagery.

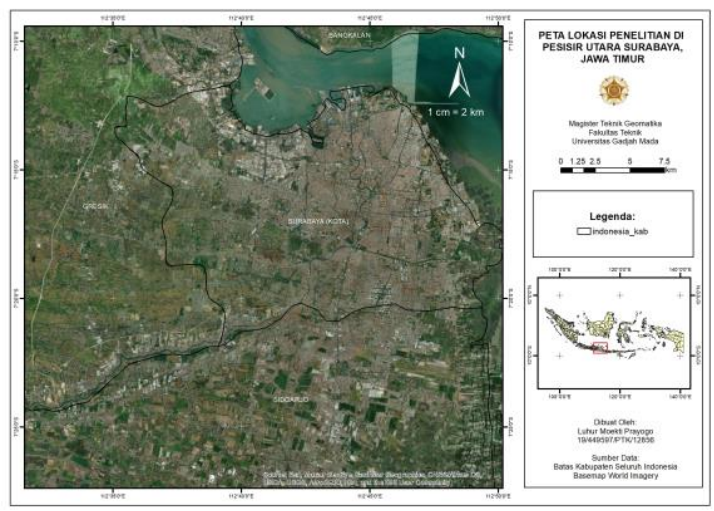

Gambar 1. Lokasi penelitian di pesisir utara Surabaya, Jawa Timur

Citra yang digunakan dalam penelitian ini adalah citra Moderate Resolution Imaging Spectroradiometer (MODIS) yang pertama kali menghasilkan rekaman obyek permukaan bumi pada tahun 2001. Citra MODIS tergolong dalam citra resolusi rendah dengan resolusi spasial 5001000 m. Karakteristik dari citra ini memiliki dua wahana yang beredar berlawanan arah yang disebut TERRA dan AQUA (NASA, 2020). Dengan memiliki dua wahana, maka citra ini mampu menyajikan resolusi temporal dengan cukup baik dengan kemampuan revisit time 1-2 hari. Untuk ketersediaan band, citra MODIS memiliki band sebanyak 36 buah. Rentang panjang gelombang yang terdapat pada keseluruhan band berkisar $0.4-14.4$ $\mu m$. Level data dalam citra MODIS terdiri dari empat (4) level, dimana dalam penelitian ini menggunakan level yang sudah di proses dan menghasilkan produk temperature.

\section{Algoritma Deteksi Suhu}

Penggunaan satelit MODIS untuk deteksi suhu pada sensor satelit menggunakan algoritma Split Window Algorithm (SWA). Rozenstein et al. (2014) menyatakan suhu kecerahan 
merupakan salah satu variabel pada band thermal. Persamaan yang digunakan untuk deteksi suhu adalah sebagai berikut (Persamaan 1):

$$
T=\frac{K 2}{\ln \left(\frac{K 1}{L \lambda}+1\right)}
$$

Dimana:
T : Suhu Radian
$\mathrm{L} \lambda \quad$ : Radiansi Spektral
K2 : 1282.71
K1 : $666.09\left(\mathrm{w} / \mathrm{m}^{*}{ }^{*}\right.$ ster* $\left.^{*} \mathrm{um}\right)$

Kemudian dilakukan konversi suhu dari radian ke suhu permukaan dengan persamaan berikut (Artis \& Carnahan, 1982) (Persamaan 2):

$$
T_{s}=\left(\frac{T_{E}}{1+\left(\frac{\lambda T_{E}}{\rho}\right) \ln \varepsilon}\right.
$$

Dimana:

Ts : Suhu permukaan
$\varepsilon \quad$ : Emisivitas
$\mathrm{T}_{\mathrm{B}} \quad:$ Suhu Radian
$\lambda^{\mathrm{S} \quad \text { Panjang gelombang }}$ yang
dipancarkan $11.5 \mu \mathrm{m}$
$\rho \quad:$ hc $/ \mathrm{K}\left(1,438 \times 10^{-2} \mathrm{mK}\right)$

\section{Pemrosesan Citra Berbasis Cloud}

Pengolahan citra satelit penginderaan jauh berbasis cloud memiliki keuntungan salah satunya tidak memerlukan penyimpanan yang besar. Salah satu platform yang mendukung pemrosesan citra digital penginderaan jauh berbasis cloud adalah Google Earth Engine (GEE). Platform ini menyediakan database citra open source di seluruh dunia, dimana data tersebut dapat diakes pengguna secara real-time. Menurut Gorelick et al. (2017), GEE merupakan platform yang disediakan oleh US Geological Survey dan NOAA yang dapat melakukan komputasi dan pemrosesan data dengan cepat. Terdapat berbagai fungsi untuk pemrosesan citra pada platform ini diataranya analisis statistika, deteksi tepi, analisis nilai bit citra dan pengujian matrik (Gorelick et al., 2017).

\section{Hasil dan Pembahasan}

Pemetaan suhu permukaan daratan dalam penelitian ini didasarkan pada pertimbangan bahwa wilayah Surabaya mengalami kenaikan suhu akibat terjadinya pembangunan wilayah. Hal ini disebabkan karena berkurangnya vegetasi dimana dialihfungsikan menjadi pemukiman atau perkantoran. Luaran yang dihasilkan merupakan rerata suhu setiap tahun dari 20002001, 2010-2011 dan 2019-2020, sehingga output dalam penelitian ini adalah tiga citra yang menggambarkan suhu daratan di wilayah Surabaya bagian utara.

Penggunaan Google Earth Engine untuk pemetaan suhu permukaan daratan diawali dengan penentuan lokasi dan pemilihan database citra yang digunakan. Script yang digunakan untuk memasukkan database citra MODIS adalah ee.imageCollection kemudian memasukkan level data MODIS yang diinginkan. Kemudian pemilihan tahun menggunakan filterDate agar yang ditampilkan merupakan data dengan waktu perekaman tahun 2000-2001. Kemudian Script select digunakan untuk memilih data MODIS yang diinginkan yaitu MODIS beresolusi spasial $1000 \mathrm{~m}$ $(1 \mathrm{~km})$.

Kemudian untuk menghasilkan rerata suhu yang dibentuk dan kemudian ditampilkan dalam satu scene citra, maka ditambahkan script mean (). Hal ini bertujuan agar hasil estimasi suhu menjadi satu scene, bukan banyak scene. Kemudian dilakukan pemilihan 
lokasi yaitu dengan clip region. Penentuan luasan wilayah yang akan dilakukan pemrosesan yaitu dengan menu geometri yang sudah tersedia di platform GEE. Gambar 2 menunjukkan penulisan script dan region yang digunakan dalam penelitian ini

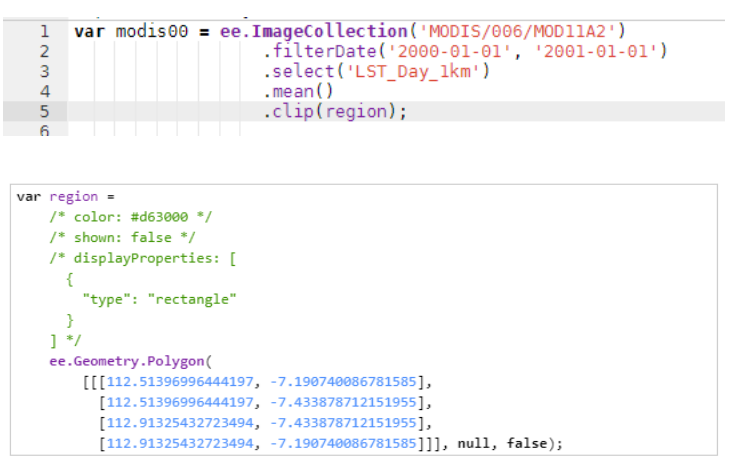

Gambar 2. Potongan script untuk deteksi suhu permukaan daratan

$\begin{array}{crr}\text { Pemberian } & \begin{array}{c}\text { definisi } \\ \text { langkah }\end{array} & \text { untukO0 }\end{array}$ mempermudah dalam pemrosesan citra (2000-2001). Analisis citra pada tahun 2010-2011 menggunakan definisi modis11 dan modis20 digunakan untuk analisis citra tahun 2019-2020. Proses analisis citra pada tahun tersebut dilakukan sama seperti tahap analisis modis00. Kemudian, pemrosesan citra MODIS dilanjutkan dengan merubah hasil nilai suhu yang didapatkan dari database MODIS dari derajat kelvin menjadi derajat celcius. Fungsi matematika sederhana yang digunakan (var modis x 0.02) - 273.15. Fungsi pengali dalam java menggunakan .multiply() dan pengurang menggunakan .subtract (). Langkah terakhir yaitu map add layer yang digunakan untuk menampilkan citra dalam tampilan RGB bukan grayscale. Gambar 3 merupakan tampilan Google Earth Engine untuk analisis suhu permukaan daratan wilayah Surabaya utara dan sekitarnya.

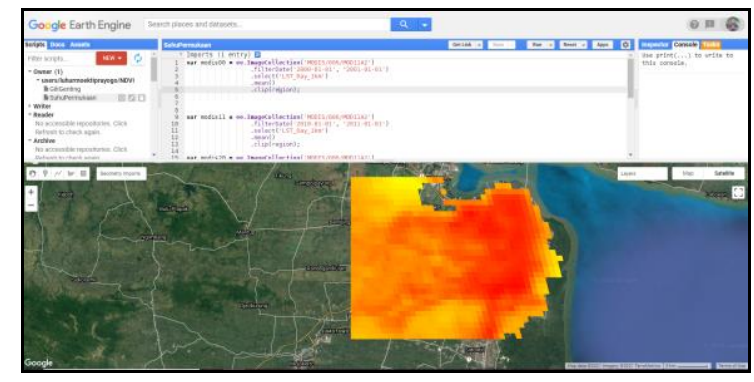

Gambar 3. Hasil analisis suhu permukaan daratan menggunakan Google Earth Engine

Pemetaan suhu permukaan darat dilakukan pada tahun 2001 hingga 2020 yang menghasilkan tiga peta. Peta yang dihasilkan merupakan rerata tahunan dari tahun 2001 hingga 2020. Citra MODIS memiliki resolusi temporal 1-2 hari, oleh karena itu dalam penelitian ini suhu tahunan dibuat rerata dengan script mean(). Hasil pemetaan menunjukkan bahwa terjadi peningkatan panas yang cukup signifikan dari tahun ke tahun. Pada tahun 2001, suhu permukaan pada kisaran $30^{\circ} \mathrm{C}$ terletak dibagian utara, namun pada tahun 2011 suhu meningkat dan menyebar ke wilayah bagian selatan dan yang paling tinggi ditunjukkan pada tahun 2020, dimana hampir keseluruhan wilayah memiliki panas diatas $28^{\circ} \mathrm{C}$. Gambar 4 merupakan tampilan peta suhu tahun 2001, 2011 dan 2020 wilayah Surabaya utara dan sekitarnya. 

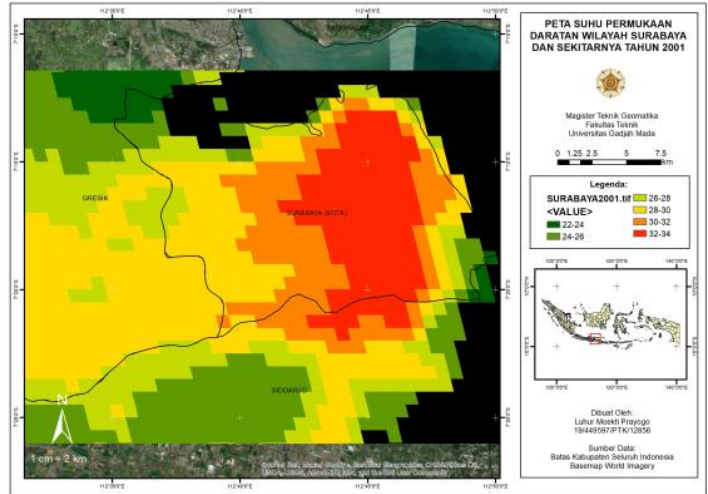

Gambar 4. Hasil pemetaan suhu permukaan darat wilayah Surabaya dan sekitarnya Tahun 2001

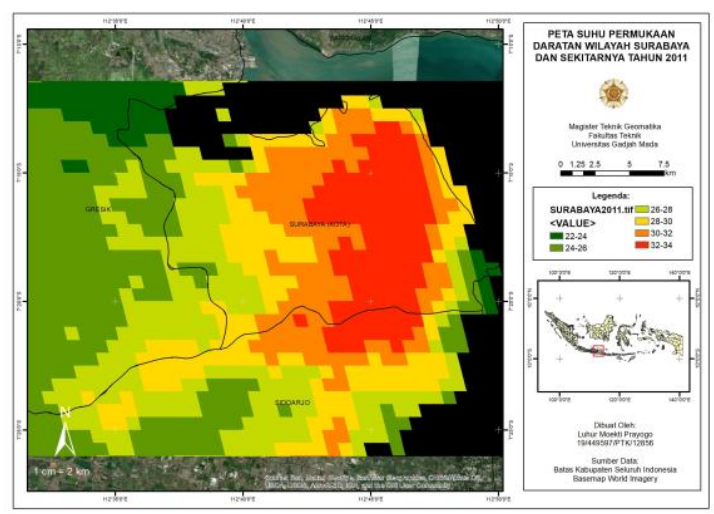

Gambar 5. Hasil pemetaan suhu permukaan darat wilayah Surabaya dan sekitarnya Tahun 2011

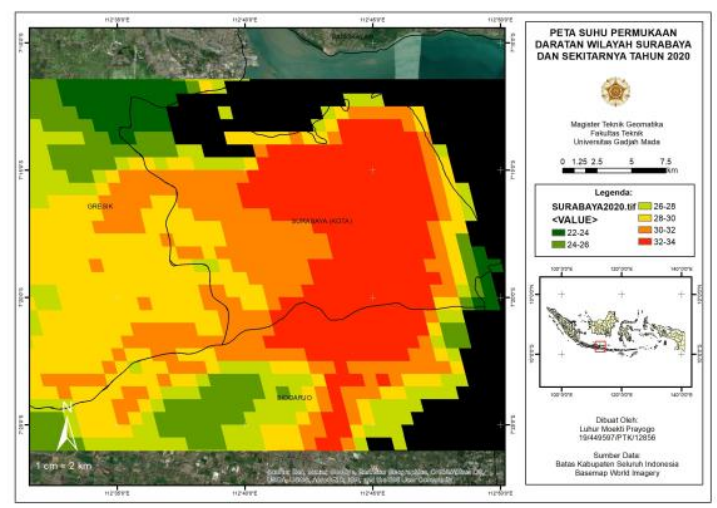

Gambar 6. Hasil pemetaan suhu permukaan darat wilayah Surabaya dan sekitarnya Tahun 2020

\section{Kesimpulan}

Dari penelitian ini dapat disimpulkan bahwa terjadi peningkatan panas yang cukup signifikan dari tahun ke tahun. Pada tahun 2001, suhu permukaan daratan pada kisaran $30^{\circ} \mathrm{C}$ terletak dibagian utara Surabaya. Pada tahun 2011 suhu meningkat dan menyebar ke wilayah bagian selatan. Kemudian suhu permukaan daratan paling tinggi ditunjukkan pada tahun 2020, dimana hampir keseluruhan wilayah memiliki panas diatas $28^{\circ} \mathrm{C}$. Dari penelitian ini menunjukkan bahwa penggunaan platform Google Earth Engine efektif untuk pemetaan suhu. Perlu adanya penelitian lanjutan mengenai penggunaan data yang diukur langsung di lapangan dan citra resolusi spasial yang lebih tinggi agar mengetahui akurasi yang dihasilkan dari platform Google Earth Engine.

\section{Ucapan Terima Kasih}

Penulis mengucapkan banyak terima kasih kepada Google yang telah menyediakan platform Google Earth Engine sehingga dapat digunakan dalam penelitian ini. Tidak lupa ucapan terima kasih kepada Labsig Inderaja yang telah memberikan pemahaman mengenai penggunaan Google Earth Engine.

\section{Daftar Pustaka}

Abutaleb, K., Ngie, A., Darwish, A., Ahmed, M., Arafat, S., \& Ahmed, F. (2015). Assessment of Urban Heat Island Using Remotely Sensed Imagery over Greater Cairo, Egypt. Advances in Remote Sensing, 4, 35-47. https://doi.org/10.4236/ars.2015.41 004.

Artis, D. A., \& Carnahan, W. H. (1982). Survey of emissivity variability in thermography of urban areas. Remote Sensing of Environment, 313-329. https://doi.org/10.1016/00344257(82)90043-8.

Fariz, T. R., Sanjoto, T. B., \& Setyowati, D. L. (2019). Komparasi Kemampuan Citra Satelit Landsat Dalam Mengidentifikasi Suhu Permukaan 
Daratan Di Kota Pekalongan Sekolah Pasca Sarjana, Universitas Gadjah Mada , Yogyakarta. Seminar Nasional Geografi III-Program Studi Pascasarjana Geografi, Fakultas Geografi, UGM, 876-886.

Firdaus, Z., Muliadi, M., \& Sari, R. P. (2019). Pemetaan Perubahan Suhu Permukaan Sebagai Dampak Pembangunan Di Kota Pontianak Menggunakan Aplikasi Sistem Informasi Geografis. PRISMA FISIKA, $7(2), \quad$ 149-157. https://doi.org/10.26418/pf.v7i2.35 950.

Gorelick, N., Hancher, M., Dixon, M., Ilyushchenko, S., Thau, D., \& Moore, R. (2017). Google Earth Engine: Planetary-scale geospatial analysis for everyone. Remote Sensing of Environment, 202, 18-27. https://doi.org/10.1016/j.rse.2017.0 6.031.

Jeevalakshmi, D., Narayana Reddy, S., \& Manikiam, B. (2017). Land surface temperature retrieval from LANDSAT data using emissivity estimation. International Journal of Applied Engineering Research, 12(20), 9679-9687.

Media Indonesia. (2019). Pesisir Utara Surabaya Berpotensi Jadi Pusat Ekonomi Baru Sumbe. Media Indonesia.

https://mediaindonesia.com/nusant ara/274438/pesisir-utara-surabayaberpotensi-jadi-pusat-ekonomi-baru (Diakses 4 Februari 2021).
NASA. (2020). MODIS- Moderate Resolution Imaging Spectroradiometer. https://modis.gsfc.nasa.gov/ (Diakses 5 Februari 2021).

Rizki, F., Situmorang, A. D. L., Wau, N., Lubis, M. Z., \& Anurogo, W. (2017). Mapping Of Vegetation And Mangrove Distribution Level In Batam Island Using SPOT-5 Satellite Imagery. Journal of Geoscience, Engineering, Environment, and Technology, 2(4), 264-267. https://doi.org/10.24273/jgeet.2017 .2.4.1002.

Rozenstein, O., Qin, Z., Derimian, Y., \& Karnieli, A. (2014). Derivation of land surface temperature for landsat-8 TIRS using a split window algorithm. Sensors (Switzerland), 4, 5768-5780. https://doi.org/10.3390/s14040576 8.

Sari, R., \& Wenang Anurogo, M. Z. L. (2018). Pemetaan Sebaran Suhu Penggunaan Lahan Menggunakan Citra Landsat 8 Di Pulau Batam. Jurnal Integrasi, 10(1), 32-39. https://doi.org/ISSN: 25489828.

Suharyo, O. S., \& Hidayah, Z. (2019). Pemanfaatan Citra Satelit Resolusi Tinggi Untuk Identifikasi Perubahan Garis Pantai Pesisir Utara Surabaya. Jurnal Kelautan: Indonesian Journal of Marine Science and Technology, $12(1)$, 89-96. https://doi.org/10.21107/jk.v12i1.5 084. 